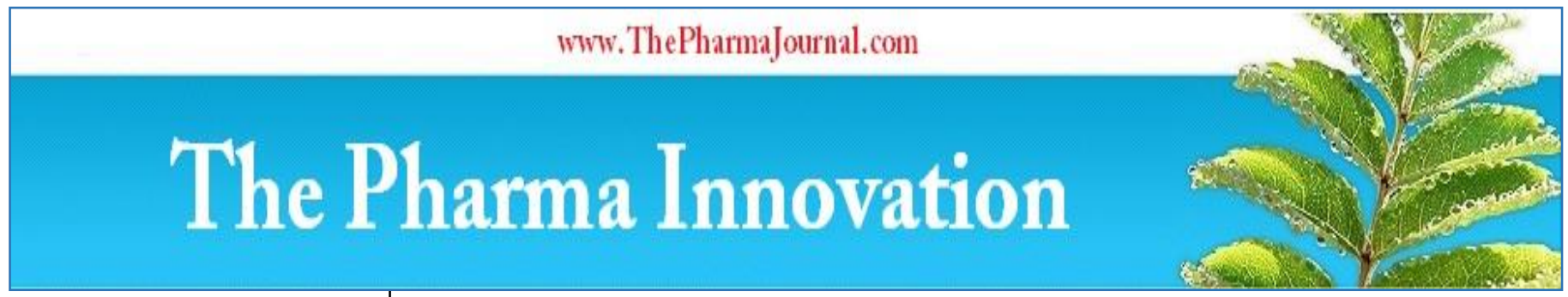

ISSN (E): $2277-7695$

ISSN (P): 2349-8242

NAAS Rating: 5.03

TPI 2021; 10(3): 397-398

(C) 2021 TPI

www.thepharmajournal.com

Received: 16-01-2021

Accepted: 18-02-2021

Saranya C

Department of Veterinary

Surgery and Radiology,

Veterinary College and Research

Institute, Namakkal,

Tamil Nadu, India

Kathirvel S

Department of Veterinary

Surgery and Radiology,

Veterinary College and Research

Institute, Namakkal,

Tamil Nadu, India

Senthilkumar S

Department of Veterinary

Surgery and Radiology,

Veterinary College and Research

Institute, Namakkal,

Tamil Nadu, India

Jagadeeswaran A

Department of Veterinary

Surgery and Radiology,

Veterinary College and Research

Institute, Namakkal,

Tamil Nadu, India

Corresponding Author:

Saranya C

Department of Veterinary

Surgery and Radiology,

Veterinary College and Research

Institute, Namakkal,

Tamil Nadu, India

\section{Cardiovascular effects of continuous rate infusion of lignocaine as an adjunct to general anaesthesia for intestinal surgery in cattle}

\author{
Saranya C, Kathirvel S, Senthilkumar S and Jagadeeswaran A
}

DOI: https://doi.org/10.22271/tpi.2021.v10.i3f.5803

\begin{abstract}
The study was carried out in 12 clinical cases of cattle to assess the cardiovascular effects of intravenous continuous rate infusion of lignocaine as an adjunct to general anaesthesia for intestinal surgeries. The animals were indiscriminately selected and categorized equally into two groups. All the animals were premedicated with dexmedetomidine and butorphanol tartrate at the dose rate of $0.5 \mu \mathrm{g}$ per $\mathrm{kg}$ and $20 \mu \mathrm{g}$ per kg body weight i.v. respectively. After five minutes of premedication, induction of anaesthesia was achieved with double drip solution containing ketamine hydrochloride $2 \mathrm{mg}$ and guaifenesin $50 \mathrm{mg}$ per $\mathrm{mL}$ respectively, administered i.v. "to effect". Anaesthesia was maintained with isoflurane in all the animals. In group II animals ten minutes prior to skin incision, slow intravenous lignocaine bolus at the dose rate of $2 \mathrm{mg}$ per $\mathrm{kg}$ and continuous rate infusion at the dose rate of $50 \mu \mathrm{g}$ per $\mathrm{kg}$ per min was delivered through volumetric infusion pump. There was no significant difference in cardiovascular parameters noticed between the group which signifies that intravenous lignocaine at this dose in anaesthetised cattle is cardiovascular dynamic.
\end{abstract}

Keywords: adjunct, cardiovascular, cattle, continuous infusion, intravenous, lignocaine

\section{Introduction}

Lignocaine is an amide group of local anaesthetic commonly employed for surgical procedures in large animals by local infiltration and nerve blocks. Intravenous administration of lignocaine has been used for regional anaesthesia and arrhythmia. Several studies have revealed that lignocaine infusion significantly reduces the minimum alveolar concentration (MAC) of inhalation agents in a variety of species including horses (Doherty \& Frazier 1998) ${ }^{[1]}$, dogs (Valverde et al. 2004) ${ }^{[2]}$ and goats (Doherty et al. 2007) ${ }^{[3]}$. However, there are no reports assessing the probable effects of intravenous lidocaine in anaesthetized adult cattle.

The plasma concentrations of lignocaine and its active metabolite, mono ethyl glycine xylidide, have different pharmacokinetic profiles when administered in the animal anesthetized with isoflurane and in the awaken animal. The volume of central compartment, clearance and elimination half-life of lidocaine are smaller in anesthetized animal than awaken animal, resulting in higher plasma concentrations of lidocaine in the anesthetized animal (Thomasy et al, 2005) ${ }^{[4]}$. Lidocaine toxicity is more likely to manifest when its plasma concentration reaches $5 \mu \mathrm{g}$ per $\mathrm{mL}$. Doses between 1 and $2 \mathrm{mg}$ per $\mathrm{kg}$ administered as bolus followed by continuous infusion of 25 to $50 \mu \mathrm{g}$ per $\mathrm{kg}$ per min reaches the plasma concentrations of $2 \mu \mathrm{g}$ per $\mathrm{mL}$ are considered nontoxic. The main objective of the study is to assess the cardiovascular properties of lignocaine administered as adjunct in anaesthetised cattle.

\section{Materials and Methods}

The study was conducted in 12 clinical cases of cattle presented for major intestinal surgical interventions under general anaesthesia at large animal surgery outpatient unit of Veterinary Clinical Complex, Veterinary College and Research Institute, Tamil Nadu Veterinary and Animal Sciences University, Namakkal. The animals were randomly divided into two groups viz., group I and group II comprising of six animals each.

The age in months and body weight in kilograms of the selected animals were recorded. In all the animals the feed and water were withheld for 24 and 12 hours, respectively before induction of anaesthesia. 
All the animals were premedicated with dexmedetomidine and butorphanol tartrate at the dose rate of $0.5 \mu \mathrm{g}$ per $\mathrm{kg}$ and $20 \mu \mathrm{g}$ per $\mathrm{kg}$ body weight i.v. respectively. After five minutes of premedication, induction of anaesthesia was achieved with double drip solution containing ketamine hydrochloride $2 \mathrm{mg}$ and guaifenesin $50 \mathrm{mg}$ per $\mathrm{mL}$ respectively, administered i.v. "to effect". Following induction oroendotracheal intubation was accomplished and the animal were connected to breathing tube of large animal anaesthetic machine (Mallard Medical INC, Model $2800 C^{\circledR}$, Redding CA 96002, USA) with built-in out of circle precision vapourizer $\left(\right.$ Forane $^{\circledR}$, Model 100, SurgiVet, USA). In group II animals ten minutes prior to skin incision, slow intravenous lignocaine bolus at the dose rate of $2 \mathrm{mg}$ per $\mathrm{kg}$ and continuous rate infusion at the dose rate of 50 $\mu \mathrm{g}$ per kg per min was delivered through volumetric infusion pump (Infuser breeze, Medilogix Medical Technologies Private Limited, Chennai, India.) till the start of skin closure. All the animals were monitored continuously during anaesthesia by instrumenting with base apex lead system of electrocardiography, a pulse oximeter (placed on the tongue), non-Invasive blood pressure cuff of Welch Allyn vital sign monitor ${ }^{\circledR}$. The data obtained were statistically compared employing one way ANOVA as described by Snedecor and Cochran (1994). The data collected were analysed using SPSS ${ }^{\circledR} 10$ software package.

\section{Results and Discussion}

The mean $( \pm \mathrm{SE})$ heart rate per min recorded before premedication, after induction, $10^{\text {th }}, 20^{\text {th }}$ and $30^{\text {th }}$ min of isoflurane anaesthesia and after recovery were $87.50 \pm 1.77$, $83.40 \pm 1.72, \quad 80.10 \pm 1.77, \quad 75.00 \pm 1.80, \quad 72.10 \pm 1.33$ and $86.10 \pm 1.30$, in group $I$ and $87.20 \pm 1.77,82.50 \pm 1.71$, $78.30 \pm 1.87,73.60 \pm 1.54,70.10 \pm 1.81$ and $86.50 \pm 1.62$ in group II animals.

The significant reduction $(\mathrm{p}<0.05)$ in heart rate during $30^{\text {th }}$ min of maintenance phase of anaesthesia observed in all animals could be attributed to the reflection of deeper plane of anaesthesia. The non-significant difference between the groups infers that the bolus dose of lignocaine given at slow rate and CRI administered throughout the maintenance phase of anaesthesia does not cause decrease in heart rate which is a clinical significance in compromised cattle. This is in divergent to the findings of Araujo et al (2014) ${ }^{[5]}$.

The mean $( \pm \mathrm{SE})$ saturation of peripheral oxygen was recorded continuously during anaesthesia were $96.90 \pm 0.67$ in group I and $97.20 \pm 0.57$ per cent in group II. The administration of 100 per cent oxygen could increase the partial pressure of oxygen substantially at alveoli and this could result in easy transfer of oxygen from alveoli to blood and increase partial pressure of oxygen in the arterial blood. Similar observations were recorded by Senthilkumar (2013) ${ }^{[6]}$.

The mean $( \pm \mathrm{SE})$ arterial pressure during low flow isoflurane anaesthesia was $87.30 \pm 2.40$ and $85.90 \pm 2.73 \mathrm{~mm} \mathrm{Hg}$ in group I and II, respectively with no significant difference between the groups. The mean arterial pressure measured during various stages of anaesthesia did not differ significantly between the groups. Thus the influence of intravenous administration of lignocaine has no execrable effect on vascular dynamics. This is in contrary to the observations of Araujo et al (2014) ${ }^{[5]}$.

The mean $( \pm \mathrm{SE})$ amplitude $(\mathrm{mV})$ of $\mathrm{P}, \mathrm{R}, \mathrm{S}, \mathrm{T}$ waves, $\mathrm{P}$ duration (sec) and PR interval (sec) and QT interval (sec) during low flow isoflurane anaesthesia were $0.21 \pm 0.07$, $1.33 \pm 0.30,0.10 \pm 0.02,0.61 \pm 0.12,0.06 \pm 0.01,0.18 \pm 0.02$ and
$0.31 \pm 0.06$, respectively in group I. In group II, these values were $0.18 \pm 0.02,1.16 \pm 0.23,0.09 \pm 0.02,0.62 \pm 0.09,0.05 \pm 0.02$, $0.17 \pm 0.02$ and $0.30 \pm 0.02$, respectively. Electrocardiography was monitored continuously during anaesthesia and no signs of arrhythmias were encountered in any of the animals.

\section{Summary and Conclusion}

The intravenous bolus and CRI dose of lignocaine at $2 \mathrm{mg}$ per $\mathrm{Kg}$ and $50 \mu \mathrm{g}$ per $\mathrm{kg}$ per min, respectively administered during general anaesthesia for intestinal surgery in cattle does not lower the heart rate and mean arterial pressure. Administration of bolus dose of lignocaine at a slow rate over a period of $10 \mathrm{~min}$ prevented sudden peripheral vasodilation and decrease in mean arterial pressure following infusion. No arrhythmia was encountered with continuous electrocardiographic monitoring of all the animals during maintenance of anaesthesia. At the studied rate lignocaine found to be cardiovascular dynamic.

\section{Acknowledgement}

The authors are thankful to the Tamil Nadu Veterinary and Animal Sciences University for the support during the study

\section{Conflict of interests}

The authors declared no potential conflicts of interest with respect to the research, authorship, and/or publication of this article.

\section{Funding}

The authors received a financial support from Tamil Nadu Veterinary and Animal Sciences University during the research.

\section{References}

1. Doherty TJ, Frazier DL. Effect of intravenous lidocaine on the minimum alveolar concentration in ponies. Equine Vet J 1998;30:300-303.

2. Valverde A, Gunkel C, Doherty TJ. Effect of a constant rate infusion of lidocaine on the quality of recovery from sevoflurane or isoflurane general anaesthesia in horses. Equine Vet J 2005;37:559-564.

3. Doherty et al. Effect of intravenous lidocaine and ketamine on the minimum alveolar concentration of isoflurane in goats. Veterinary Anaesthesia and Analgesia 2007;34(2):125-131.

4. Thomasy SM, Pypendop BH, Ilkiw JE, Stanley SD. Pharmacokinetics of lidocaine and its active metabolite, mono ethyl glycine xylidide, after intravenous administration of lidocaine to awake and isofluraneanesthetized cats. AJVR 2005;66(7):1162-1166.

5. Araujo et al. Cardiovascular effects of a continuous rate infusion of lidocaine in calves anesthetized with xylazine, midazolam, ketamine and isoflurane. Vet. Anaes. Analg 2014;41:145-152.

6. Senthikumar S, Rajendran N, Dharmaceelan S, Kathirvel S, Subramaniyan S, Selvaraj P. Fresh gas flow reduction and isoflurane sparing effect of butorphanol and buprenorphine during low flow isoflurane anaesthesia in cattle. Indian J. Vet. Surg 2013;34:88-90. 